\title{
Evidencia de cazadores especializados en el sitio de La Gloria, Golfo de Urabá
}

\author{
Gonzalo Correal Urrego
}

Rev. Acad. Colomb. Cienc. Ex. Fis, Nat. 1983, 15 (58): 77-82.

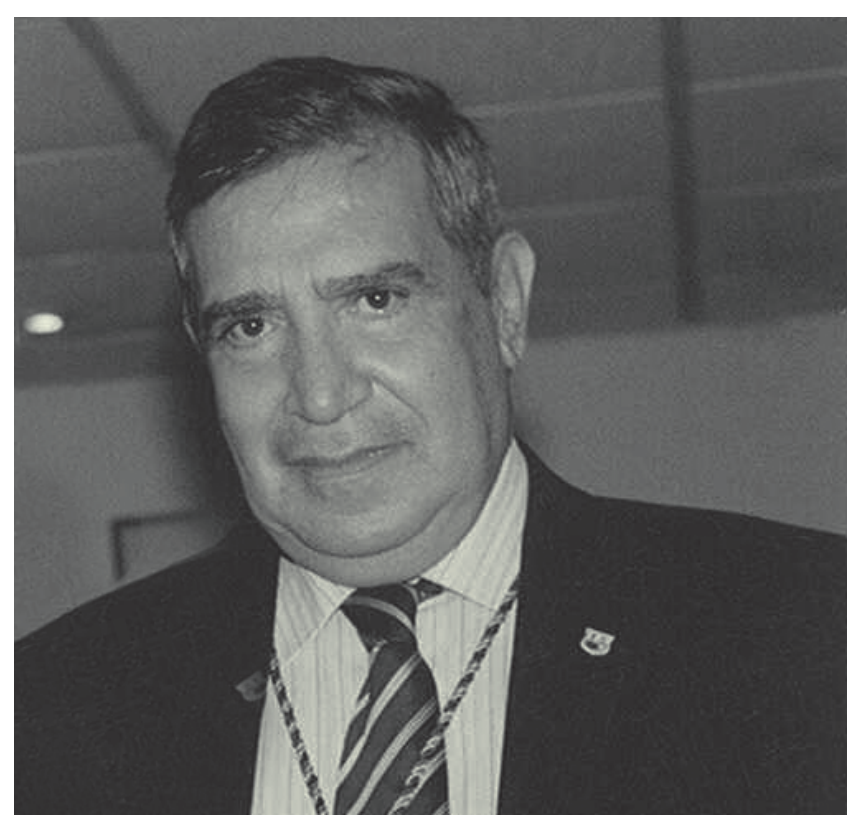

\section{Gonzalo Correal Urrego (1939)}

Es uno de los principales antropólogos de Colombia. Nació en Gachalá (Cundinamarca). Obtuvo su grado en antropología en el Instituto Colombiano de Antropología e Historia, y de doctor en derecho en la Universidad Libre. Trabajó en la Universidad de Antioquia entre 1968 y 1971, y luego, por espacio de más de 20 años en la Universidad Nacional de Colombia en Bogotá, en donde fue director del Instituto de Ciencias Naturales. Sus investigaciones en antropología, paleontología y arqueología, algunas de ellas en colaboración con el académico Thomas van der Hammen, han tenido gran reconocimiento nacional e internacional. Se centraron en el período precerámico en Colombia (en El Abra, Tequendama, Aguazuque y Tibitó, entre otros sitios arqueológicos). Encontró en El Abra evidencia de asentamientos humanos 12.400 años a. p., uno de los primeros en América del Sur.

El profesor Correal fue honrado con el Primer Premio Nacional de Antropología y Arqueología en 1975, elevado a la categoría de Profesor Emérito de la Universidad Nacional de Colombia en 1983, de Maestro Universitario en 1994 y de Profesor Honorario de la misma Universidad en 1995, en la cual le fue reconocida su trayectoria científica de 40 años con el Premio Vida y Obra en el año 2007.
El presente artículo sobre cazadores especializados en La Gloria (Chocó, Darién colombiano), en inmediaciones del municipio de Acandí, presenta nuevos hallazgos que se enmarcan en los trabajos anteriores del autor sobre la temprana presencia de pobladores humanos en el norte de Suramérica. El trabajo de investigación arqueológica es sistemático y presenta evidencias de poblamiento precolombino que incluyen fragmentos de urnas funerarias $y$, particularmente, un hacha pulimentada de tipo Clovis, primera de su género en la zona tropical.

Cerca de la casa de la hacienda La Gloria se ubica la Cueva de los Murciélagos. A la entrada, y asociada a tres guijarros de basalto redondeados y fragmentados, encontró un hacha trapezoidal de basalto. El artículo describe en detalle esta hacha, con punta de proyectil tipo "cola de pescado". Este es el primer ejemplar hallado en Colombia. Se analiza su importancia y su relación con instrumentos similares encontrados en Norteamérica.

Correal Urrego señala que, con base en este hallazgo, habría sido por esa zona por donde se realizó el tránsito de cazadores prehistóricos en dirección norte-sur, desde el Istmo de Panamá hacia la costa norte de Colombia, durante el Pleistoceno.

Encontró también, por medio de procedimientos de arqueología sub-acuática, fragmentos correspondientes a urnas funerarias a 20 metros de la playa.

El análisis arqueológico de la punta lanceolada acanalada de la Cueva de los Murciélagos se presenta en detalle y es un aporte especialmente relevante en la investigación del poblamiento americano. Sobre uno de los bordes presenta retocado por presión y sus rasgos generales muestran su posible utilización como instrumento raspante. El autor afirma que es lógico suponer que los portadores de puntas de lanza acanaladas fueron cazadores superiores, aunque el hallazgo del Darién no muestra asociación específica con megafauna.

Rubén Ardila, Ph.D.

Miembro de número 


\title{
EVIDENCIA DE CAZADORES ESPECIALIZADOS EN EL SITIO DE LA GLORIA, GOLFO DE URABA
}

\author{
Por GONZALO CORREAL URREGO \\ Departamento de Antropología \\ Instituto de Ciencias Naturales \\ Universidad Nacional de Colombia
}

\section{SINTESIS GEOGRAFICA Y UBICACION DEL SITIO ARQUEOLOGICO}

Con el nombre de la Gloria (Foto 1) se conoce el sitio localizado en el Depto. del Chocó (Darién chocoano), en el municipio de Acandí, al sureste de esta población. En este sector, se destacan la bahía Gloria y la isla de la misma denominación. El sitio arqueológico la Gloria se localiza entre las coordenadas $8015^{\prime}$ latitud Norte y 770 7' de longitud al Oeste de Greenwich; en proximidades del corregimiento de Titumate (aproximadamente $4.5 \mathrm{Km}$. al S.E. de esta población).

En el sector alternan las superficies planas costaneras con las estribaciones de la Serranía del Darién.

Las principales fuentes hidrográficas que bañan este sector son: los ríos Tislo, Tanelita y caños tributarios del Tanela.

Altura sobre el nivel del mar $4 \mathrm{~m}$.; temperatura media $28^{\circ} \mathrm{C}$.

\section{GEOLOGIA}

En el área de bahía Gloria pueden reconocerse rocas volcánicas continentales, principalmente flujos de lodo volcánico y tobas de composición andesítica a dacítica. Entre las unidades litoestratigráficas se diferencian basalto, andesita, chert, radiolarita, limolita y caliza. También son reconocibles rocas sedimentarias de Oligoceno al Plioceno, sedimentos marinos, predominantemente arcillo-arenosos, y localmente conglomerados y calizas.

\section{SUELOS}

En el conjunto de los suelos de esta área, pueden diferenciarse abanicos del sector Titumate (Eutropepts, tropopsamment); asociación (TI), ubicada dentro del bosque húmedo tropical (bh-t) que agrupa suelos de relieve plano, eutróficos y con texturas contrastantes, marcadamente influenciadas por los sedimentos arenosos depositados por el mar (Proyecto Darién 1978 pág. 11).

\section{VEGETACION}

En sus rasgos generales comprende bosque húmedo tropical (bh-t); de acuerdo con los estudios sobre el área, "esta formación vegetal, ocupa el 24.290 del territorio del Darién encontrándose en el rango de 1.900 a $3.100 \mathrm{~mm}$. de precipitación anual. Entre el nivel del mar y unos 400 metros de elevación, la biotemperatura se mantiene relativamente constante entre 24.5 y $25.0{ }^{\circ} \mathrm{C}$ en la parte seca, y entre 25.0 y $25.30^{\circ} \mathrm{C}$ en la parte más húmeda" (Proyecto Darién 1978, pág. 75).

\section{INVESTIGACION ARQUEOLOGICA}

Este sector geográfico de la Gloria, ha sido objeto de dos reconocimientos arqueológicos; el primero efectuado durante 1973*, durante el cual se obtuvieron evidencias de poblamiento precolombino que incluyen fragmentos de urnas funerarias, y un hacha pulimentada, cuya correspondencia cronológica y cultural no dudames en asignar a desarrollos agrícolas tardíos que debieron tener lugar en el litoral hacia los propios albores de la conquista.

Se hallaron también evidencias precerámicas en esta área, durante el primer reconocimiento, y consisten en una punta de proyectil tipo "cola de pescado" obtenida a aprox. $80 \mathrm{~m}$. en dirección S.E. de

\footnotetext{
* El reconocimiento de la referencia organizado por el Ministerio de Educación ICAN, con la colaboracion de la Armada Nacional, tuvo como objetivo primordial la localización de Santa María la Antigua del Darién. Integraron la comisión los Padres Fray Alberto Lee L. y Javier Montoya S., Drs. Mauricio Obregón, Reinaldo Quintero, Hernán Correa, Señor Mauricio Londoño, Señorita Julia Mejía, Señor E. Dumas y el autor de este artículo.
} 


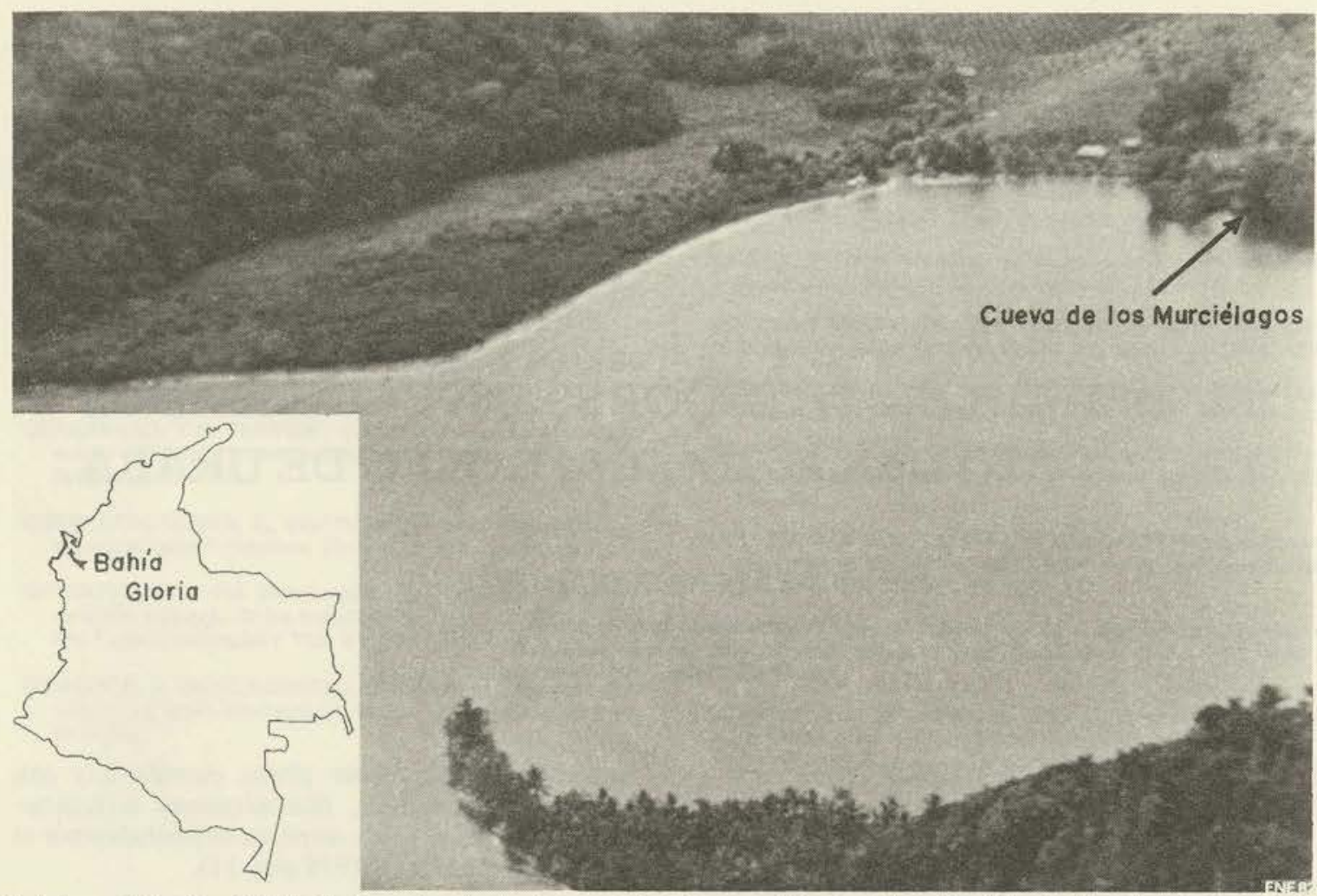

Foto 1. Vista aérea de bahía Gloria, mostrando el extremo sur de la isla y parcialmente el dique. En el litoral está señalada la Cueva de los Murciélagos.

la casa de la hacienda "La Gloria", en un playón en el que abundan guijarros de cuarzo, andesitas y basaltos. Durante esta primera exploración fue localizada a unos $60 \mathrm{~m}$. al NW de la casa de la hacienda, una cueva de origen natural producida por la acción de las aguas sobre las rocas de origen volcánico y por la exfoliación de éstas. Esta formación espeleológica conocida hoy como "Cueva de los Murciélagos", presenta las siguientes características:

Anchura de la entrada $4.40 \mathrm{~m}$.

Altura promedio en el sector de la entrada $4 \mathrm{~m}$.

Longitud total $14 \mathrm{~m}$.

Longitud de la bóveda $6 \mathrm{~m}$.

Altura promedio de la bóveda $2.5 \mathrm{~m}$.

En desarrollo de esta inicial prospección, se efectuaron varios sondeos, hasta $10 \mathrm{~m}$. de la entrada dela cueva, llegando al suelo rocoso basal, a poca profundidad $(0.50 \mathrm{~cm}$.). Un test arqueológico consistente en una cuadrícula de $2 \times 2 \mathrm{~m}$., dividida en 4 sub-unidades de un metro cada una para efectos de control, junto a la entrada nos permitió determinar 2 unidades estratigráficas en este sector de la cueva: 1. arenoso-pardusco, 2. arenoso-gris. Estas unidades, reposan inmediatamente encima de la roca. Un perfil en la cámara de la cueva practicado durante un segundo reconocimiento (Noviembre de 1981), que se efectuó en desarrollo del plan de estudios Medio Ambiente Pleistocénico y Hombre Prehistórico en Colombia, que actualmente desarrolla el Instituto de Ciencias Naturales-Museo de Historia Natural de la Universidad Nacional, con el apoyo financiero de la Fundación Arqueológica del Banco de la República, nos permite establecer la siguiente estratigrafía:

0-45 cm. arenoso pardusco

$45-55 \mathrm{~cm}$. arenoso gris

$55-70 \mathrm{~cm}$. arcilloso amarillento

$70-80 \mathrm{~cm}$., grisáceo hasta roca.

A la entrada de la cueva, y asociada a tres guijarros de basalto redondeados y fragmentados, producidos por exfoliación de la roca, fue localizada un hacha trapezoidal de basalto cuyas características son las siguientes:

Dimensiones:

Longitud: $115.9 \mathrm{~mm}$.

Ancho máximo: $53.1 \mathrm{~mm}$.

Espesor: $26.2 \mathrm{~mm}$.

Este artefacto, presenta filo arqueado, cabo ligeramente redondeado, sección rectangular, superficie bien pulimentada, y corresponde a la clasificación centrada (García Cook 1967, pág. 100).

Durante esta primera visita, se pudo reconocer un dique de piedra que se extiende desde el extremo sur de la isla Gloria hasta el litoral (Foto 1); de acuerdo con el concepto del Dr. Reinaldo Quintero (Geomorfólogo), esta formación es de carácter natural. Un reconocimiento de arqueología sub-acuática, efectuado en la bahía hasta $20 \mathrm{~m}$. de la playa, nos permitió recolectar algunos fragmentos cerámicos correspondientes a urnas funerarias; unos pocos fragmentos óseos se encontraban asociados a uno 
de estos elementos, dentro de la arena: esta situación, nos está indicando que cuando se practicaron los enterramientos secundarios en el sitio, la línea de la costa se encontraba más hacia afuera.

Durante la segunda exploración en la "cueva de los Murciélagos" pudimos reconocer otra punta de proyectil, en el sector de la cámara de esta cueva; en este caso se trata de una punta de proyectil lanceolada, asociada al estrato arcillo-amarillento.

Descripción de la punta de proyectil, tipo "cola de pescado" (Foto 2, a,b). En sus rasgos generales este artefacto recuerda el tipo de puntas de lanza "cola de pescado" descritos por Bird y Cook (1977 figs. 4-7). fueron favorables para el desplazamiento de grupos de cazadores hacia nuestro territorio durante el Pleistoceno.

Lynch (1976-78) siguiendo las tesis de Sauer sugiere la existencia en el lado pacífico del istmo, de un corredor seco que habría permitido el acceso a Suramérica. Por otra parte, especialmente al noroeste del continente y en la selva amazónica, vastas áreas de selva tropical se habían cubierto de vegetación tipo sabana. Lothrop (Salazar 1979 p. 14), ha sugerido el establecimiento de bosque montano en la región del Darién, lo cual habría facilitado el paso del hombre a Suramérica. Aunque no se cuenta allí tampoco con abundante material, la escacés de estos elementos hace que cada hallazgo sea con-

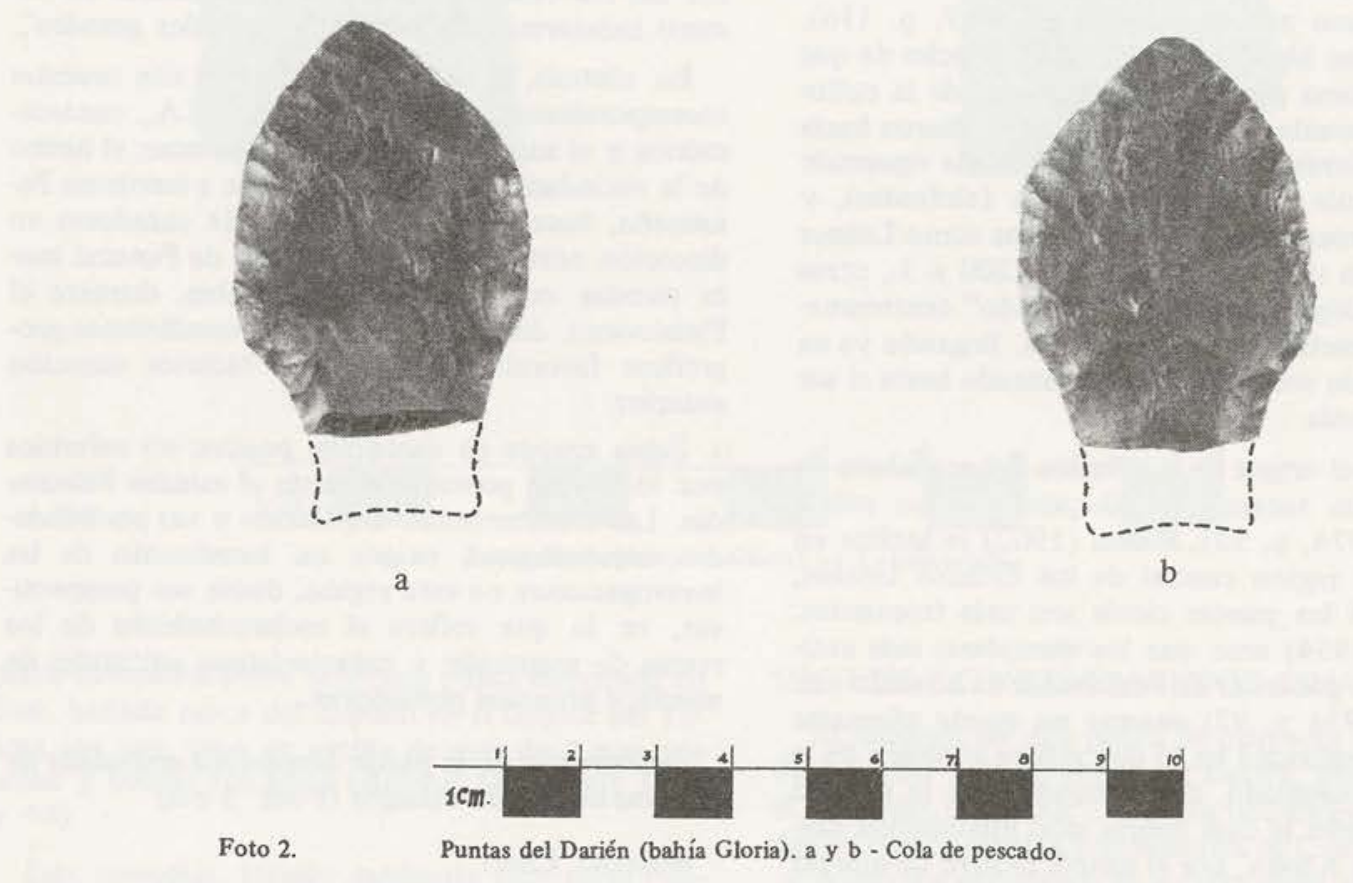

Material: chert

Longitud estimada: $66 \mathrm{~mm}$.

Longitud incompleta: $58 \mathrm{~mm}$.

Anchura máxima: $40 \mathrm{~mm}$.

Espesor hacia el extremo distal: $40 \mathrm{~mm}$.

Ancho de la hoja en la ruptura: $24 \mathrm{~mm}$.

Grosor en el centro de la hoja: $6 \mathrm{~mm}$.

Grosor maximo: $61 \mathrm{~mm}$.

Grueso máximo en el área basal: $52 \mathrm{~mm}$.

Tamaño de la lasca de acanalamiento: $17 \times 16$

Peso en gramos: 15 .

Este artefacto muestra retoques por presión tanto en el borde como en el hombro, y porción conservada del pedúnculo (Foto $2 \mathrm{a}-\mathrm{b}$ ).

La importancia de este hallazgo radica en que representa para Colombia el primer ejemplar de puntas de "cola de pescado", con una procedencia geográfica exacta; su proximidad al territorio panameño, sugiere la difusión de esta tradición de puntas de proyectil desde el istmo hacia nuestro territorio; como bien se sabe, las condiciones geográficas siderado con el máximo interés, como señalan Bird y Cook (1977, pág. 1) refiriéndose a las áreas por ellos estudiadas:

"En América Central, sin embargo, se han encontrado tan raras veces restos culturales pertenecientes a la época paleoindia que cada hallazgo, cada pedacito de evidencia merece considerarse".

En cuanto a los orígenes de esta tradición de puntas de proyectil acanaladas señala Schobinger:

"Lo que se inclinan a creer todos los investigadores, a base de la típica acanaladura (en una sola o en ambas caras) artiticio que exigía gran habilidad, destinado a facilitar el firme enmangamiento del proyectil, es que en último caso este "horizonte" se enraíza con el complejo Llano de los Estados Unidos, o por lo menos, que las puntas constituyen un derivado de las Clovis. Lynch, por ejemplo, dice que "las puntas acanaladas de El Inga son, en realidad, más parecidas a las puntas Clovis que 10 que tenemos derecho a esperar, teniendo en cuenta la distancia que media entre ambos grupos. Me re- 
sulta inconcebible que no estén íntimamente relacionados tanto cultural como cronológicamente". (1967 a, p. 19). Diversos hallazgos de puntas acanaladas fluted points, semejantes algunas a Clovis y otras más bien a folsom, han sido hechas en Méxi$\mathrm{co}$, Guatemala, Honduras y Costa Rica. La serie más interesante procede de recolecciones efectuadas en las márgenes del lago La Alajuela, embalse situado al este del Canal de Panamá. Un ejemplar entero y dos rotos muestran acanaladuras; el primero es una hermosa pieza que en su forma y tamaño constituye un intermedio entre las puntas Clovis y las de El Inga, mientras que una de las otras se asemeja definitivamentє a estas últimas". (Schobinger, 1969 pág. 116).

Este mismo autor (Schobinger 1969, p. 116), plantea como hipótesis de trabajo, el hecho de que mientras buena parte de los cazadores de la cultura Llano, durante el X milenio, se expandieron hacia el Este y Noreste de los Estados Unidos siguiendo probablemente su fauna preferida (elefantes), y hacia el Suroeste, donde yacimientos como Lehner y Naco, han sido fechados hacia 9.200 a. J., otros grupos se dirigieron hacia el "embudo" centroamericano y penetraron en Suramérica, llegando ya en el IX milenio una importante avanzada hasta el sur de la Patagonia.

Aunque el origen de la invasión del acanalado no se encuentra totalmente dilucidado como sefiala Krieger (1974, p. 93), Mason (1962) se inclina en favor de la región central de los Estados Unidos, porque allí las puntas clovis son más frecuentes; Wilthoff (1954) cree que los ejemplares más antiguos deben proceder de Pensilvania de acuerdo con Krieger (1974 p. 92) aunque no puede afirmarse nada con seguridad en lo que refiere al origen de la tarea del acanalado, debe abandonarse la antigua creencia según la cual habría sido introducida desde Asia vía Alaska, por el simple motivo de que no se le encuentra en Asia. Para Krieger (1974, p. 92) "se trata de una invención americana, pero cuyo punto de origen no puede todavía ser determinado".

En lo que refiere a ejemplares centroamericanos, señalan Bird y Cook (1977: 3) la sustancial semejanza entre ejemplares procedentes de Guatemala, Costa Rica y Panamá a los cuales se les puede clasificar junto con las puntas clovis de Norte América, no obstante algunas diferencias apreciables como mayor estrechez en la base, en los ejemplares Centro Americanos. "A excepción de dos especímenes del tipo clovis, sefralan los mismos autores (Bird y Cook 1977 pág. 15), todas las puntas acanaladas de Panamá se asemejan a las de pedúnculos en forma de "cola de pescado" encontradas en el Inga Ecuador a las de las cuevas Fel y Pallí Aike, cueva del estrecho de Magallanes (Bird 1946 y 1969); a otros similares encontrados en Uruguay, al sur del Brasil y Argentina (Schobinger, 1973) y al único especimen del Perú".

Aunque hasta la actualidad no han sido halladas en Centro América puntas de proyectil asociadas a megafauna, cree Bird $(1977$, p. 22) que la poca evidencia centroamericana concuerda todavía con la migración repentina de cazadores de la megafauna del Pleistoceno desde más al norte, entre 10.000 y 9.000 años a.C.

Es lógico suponer que los portadores de puntas de lanza acanaladas en nuestro territorio, fueron cazadores superiores, aunque el hallazgo del Darién no muestra asociación con megafauna.

En lo que relaciona con la posible cacería de megafauna en territorio Panameño, seffalan Bird y Cook (1977, p. 22): "El hecho de que algunas de las puntas de lanza acanaladas encontradas en el lago Alajuela, hayan sufrido roturas durante su uso, indica que a fines de la época del Pleistoceno a orillas del río Chagres, un grupo de cazadores de número indeterminado perseguía animales grandes".

En síntesis, el hallazgo del Darién nos muestra correspondencias tipológicas entre N.A., centroamérica y el sur del continente americano; el hecho de la vecindad del sitio de la Gloria a territorio Panameño, hace posible el tránsito de cazadores en dirección norte sur, desde el istmo de Panamá hasta nuestra costa norte de Colombia, durante el Pleistoceno, dada la ocurrencia de condiciones geográficas favorables a las cuales hicimos mención anterior.

Estos grupos de cazadores pueden ser referidos por lo menos provisionalmente al estadio Paleoindio. Las características del Darién y sus posibilidades arqueológicas, exigen un incremento de las investigaciones en esta región, dadas sus perspectivas, en lo que refiere al esclarecimiento de los restos de migración y características culturales de nuestros primeros pobladores.

Descripción de la punta lanceolada acanalada de la cueva de los Murciélagos (Foto $3 \mathrm{c}-\mathrm{d}$ )

Material: Chert

Longitud estimada: $84.9 \mathrm{~mm}$.

Anchura máxima sobre las aletas: $34.6 \mathrm{~mm}$.

Anchura de la base del pedúnculo: $14 \mathrm{~mm}$.

Espesor máximo: $7.5 \mathrm{~mm}$.

Espesor de la acanaladura del pedúnculo: $65 \mathrm{~mm}$. Tamaño de las lascas de acanalamiento:

a) $34 \times 26$

b) $43.5 \times 10.2$

Este artefacto (ver Foto $3 \mathrm{c}$-d) presenta bordes convergentes rectilíneos, aletas cortadas rectas, pedúnculo con bordes paralelos rectilíneos (ligeramente convergentes) y extremo cóncavo. Hacia los bordes presenta retoques por presión, lo mismo que hacia el hombro y el pedúnculo; sobre uno de los bordes, el artefacto presenta retocado por presión y sus rasgos generales muestran su posible utilización como instrumento raspante.

\section{HALLAZGOS SIMILARES EN COLOMBIA}

Puntas de proyectil lanceoladas, provenientes de hallazgos ocasionales han sido anteriormente descritas y figuradas (Reichel Dolmatoff 1965 p. 46); 


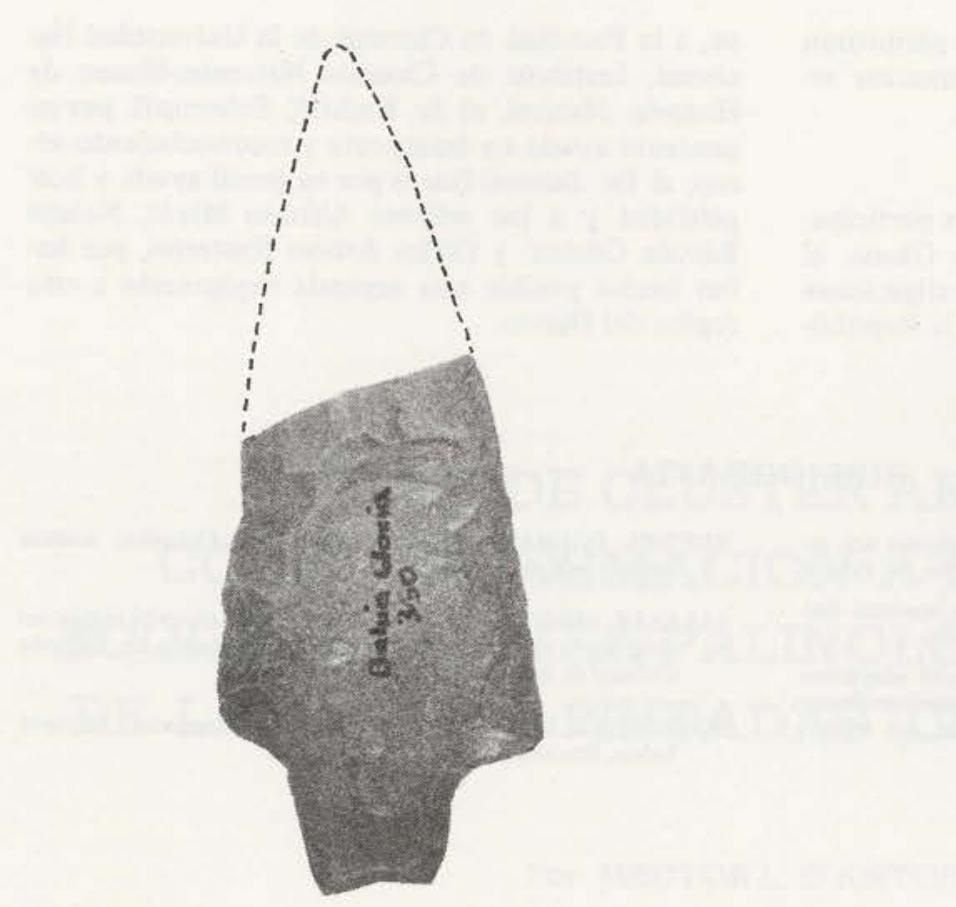

c

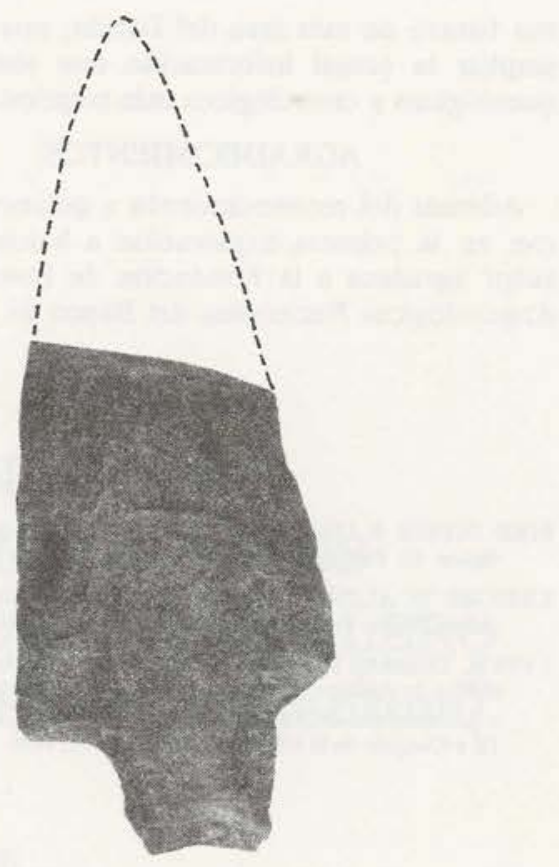

d

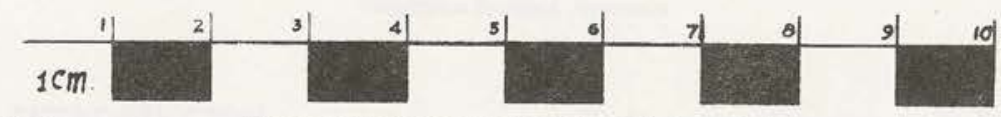

Foto 3.

Puntas del Darién (bahía Gloria). c y d - Lanceolada.

quien menciona entre otras una punta elaborada en flint, hallada cerca del Espinal en el Depto. del Tolima, en una capa de arcilla de más de $7 \mathrm{mts}$., de arena y ceniza volcánica (Reichel Dolmatoff 1965 p. 46).

Este ejemplar, tallado mediante percusión controlada muestra lados poco acerrados y retoques oblicuos paralelos, con rasgos superficiales semejantes a los señalados para las puntas Norteamericanas llamadas Angostura (Reichel Dolmatoff 1965 p. 147). La punta de proyectil lanceolada encontrada en la cueva de los Murciélagos (golfo del Darién), concuerda en sus rasgos superficiales con un ejemplar proveniente de la Cordillera Occidental, en la localidad de Restrepo (Valle). Este ejemplar, tallado bifacialmente por percusión muestra además retoques secundarios irregulares hacia los bordes (Reichel Dolmatoff 1965 p. 147). Estos rasgos junto con las acanaladuras y características del pedúnculo, también muestran la afinidad tipológica de estos elementos. Hemos podido comparar este ejemplar con dos artefactos hallados en la superficie y ocasionalmente provenientes del Depto. de Antioquia, los cuales muestran características muy similares. Particularmente el ejemplar 26.41 proveniente de la región del río Niquía, Depto. de Antioquia, que reposa en el Museo de la Universidad. Estos elementos son actualmente objeto de estudio por el arqueólogo Gerardo Ardila.

\section{SINTESIS Y CONSIDERACIONES FINALES}

El hallazgo de una punta de proyectil tipo "cola de pescado", en el golfo del Darién, bahía Gloria (Colombia) tanto por los rasgos tipológicos concordantes con elementos provenientes de Centro América, como por su propia ubicación geográfica próxima a territorio Panameño, sugiere el ingreso de cazadores superiores paleoindios desde aquellas áreas hacia territorio colombiano probablemente desde tiempo del Pleistoceno Tardío, período durante el cual como fue señalado, se dieron condiciones favorables para el tránsito humano a través del Istmo de Panamá. El hallazgo de otro tipo de punta de proyectil, en este caso lanceolada, proveniente de la cueva de los Murciélagos "bahía Gloria", nos está indicando la ocurrencia de una tradición lítica aparentemente posterior; artefactos de este tipo, han sido registrados en el Depto. de Antioquia y Depto. del Valle (Restrepo), aunque la punta lanceolada del Darién, no se encontró asociada a otros elementos arqueológicos que hicieran posible su interpretación dentro de un contexto cultural más amplio, y no se obtuvieron en la unidad estratigráfica a la cual se encuentra asociada, elementos que permitan su datación mediante Radio-Carbón, sus características tipológicas nos permiten provisionalmente asignarla a tiempos precerámicos.

Sólo la continuidad de los trabajos arqueológicos sistemáticos, que hemos proyectado para un próxi- 
mo futuro en esta área del Darién, nos permitirán ampliar la actual información con elementos arqueológicos y cronológicos más amplios.

\section{AGRADECIMIENTOS}

Además del reconocimiento a quienes participaron en la primera exploración a bahía Gloria, el autor agradece a la Fundación de Investigaciones Arqueológicas Nacionales del Banco de la Repúbli- ca, a la Facultad de Ciencias de la Universidad Nacional, Instituto de Ciencias Naturales-Museo de Historia Natural, al Sr. Rudolff Schrimpff, por su generosa ayuda en transporte y reconocimiento aéreo, al Dr. Samuel Isaacs por su gentil ayuda y hospitalidad y a los señores Alfonso Marín, Nelson Rincón Gómez y Carlos Arturo Restrepo, por haber hecho posible una segunda exploración a esta región del Darién.

\section{BIBLIOGRAFIA}

BIRD JUNIUS \& COOK RICHARD. 1979. Los artefactos más antiguos de Panamá. Rev. Nacional de Cultura No. 6, Panmá.

KRIEGER D. ALEX 1974. El hombre Primitivo en América. Ediciones Nueva Visión SAIC. Buenos Aires, Argentina.

LYNCH, THOMAS F. 1976. The Entry and post-glacial adaptation of Man in Andean South America. En habitats humanis antérieurs a L'Holocene en Amérique, James B. Griffin, ed., pp. 69-100 IX e Congrés de la UISPP, Colloque XVII, Nisa.
REICHEL DOLMATOFF, GERARDO 1965. Colombia ancient peoples and places. Hudson, London.

SALAZAR, ERNESTO 1979. El hombre temprano en la región del Ilalo Sierra del Ecuador. Publicaciones del Depto. de Difusión Cultural de la Universidad de Cuenca.

SCHOBINGER JUAN 1969. Prehistoria de Suramérica. Editorial Labor, Barcelona. 